\title{
The Relationship between Family History of Diabetes and Diabetes by BMI and Age in Korean Men and Women
}

\author{
Eunna Ko ${ }^{*}$ and Jae Woong Sull ${ }^{\dagger ; * *}$ \\ Department of Biomedical Laboratory Science, College of Health Sciences, \\ Eulji University, Seongnam, Gyeonggi-do 13135, Korea
}

\begin{abstract}
Diabetes is mainly evaluated by fasting blood sugar. The genetic and environmental factors influence the development of type 2 diabetes. In this study, the relationship between diabetes and family history of diabetes in Koreans was analyzed in consideration of body mass index and age. The study subjects were 4,274 subjects who received a medical examination at a university hospital. The main statistical analysis method was multiple logistic regression analysis. In addition, subjects were analyzed by dividing them by gender and the median of age and body mass index. Diabetes prevalence was $8.9 \%$ of all subjects, and subjects with a family history of diabetes were $14.5 \%$. The risk of diabetes was 2.80 times higher in subjects with a family history of diabetes than subjects without a family history of diabetes. In addition, in younger subjects, the risk of diabetes was 3.36 times higher in subjects with a family history of diabetes compared with subjects without a family history of diabetes. In this study, the family history of diabetes was significantly associated with diabetes. The relationship between family history of diabetes and diabetes was slightly higher in the younger group than in the older group. In order to obtain an accurate assessment of the association between diabetes and family history of diabetes, further prospective cohort study in the future is necessary.
\end{abstract}

Key Words: Family history, Diabetes, Obesity, Age

\section{서 론}

당뇨병은 주로 공복 시 혈당으로 평가된다(Ogata et al., 2018). 당뇨병은 국내외에서 증가하고 있다(Unwin et al., 2011; KCDC, 2012). 2010년 한국의 국민건강영양조사 자 료에서 당뇨병 가족력은 공복혈당 외에도 허리둘레, 중성 지방과 같은 대사증후군의 요소들도 증가시키는 것으로 보고하였다(Park et al., 2013).

제 2 형 당뇨병의 발생에는 유전적 요인과 환경적 요인 이 영향을 미치는 것으로 보고되었다(Kaprio et al., 1992). 제 2 형 당뇨병 환자의 가족력이 있는 대상자들은 가족력
이 없는 대상자들에 비하여 고혈당이 생길 위험이 3배 정 도 높았다(Shaw et al., 1999; Weijnen et al., 2002). 한편 최근 송민규 등에 연구에서는 당뇨병 가족력을 갖고 있는 대 상자들이 고혈압, 이상지질혈증, 허혈성 심장질환 가족력 을 동시에 갖고 있는 경우가 당뇨병 가족력을 갖고 있지 않는 대상자들에 비해 높았지만 뇌졸중 가족력은 유의한 차이를 보이지 않았다(Song et al., 2017).

한편, 한국인 대상 연구에서 비만은 심혈관질환의 위험 을 높임을 보고하였다(Jee et al., 2006). 해외에는 당뇨병 가족력과 당뇨병의 상관관계를 연령과 체질량지수(BMI) 를 고려하여 다룬 연구가 있지만 국내에는 당뇨병에 대 한 당뇨병 가족력의 상관관계를 연령과 $\mathrm{BMI}$ 를 고려한

Received: December 20, 2021 / Revised: December 28, 2021 / Accepted: December 28, 2021

${ }^{*}$ Researcher, ${ }^{* *}$ Professor.

${ }^{\dagger}$ Corresponding author: Jae Woong Sull. Department of Biomedical Laboratory Science, College of Health Sciences, Eulji University, 553 Sansungdaero, Seongnam, Gyeonggi-do 13135, Korea.

Tel: +82-31-740-7318, Fax: +82-31-740-7354, e-mail: jsull@eulji.ac.kr

(C) The Korean Society for Biomedical Laboratory Sciences. All rights reserved.

(c) This is an Open Access article distributed under the terms of the Creative Commons Attribution Non-Commercial License (http://creativecommons.org/licenses/by-nc/3.0/) which permits unrestricted non-commercial use, distribution, and reproduction in any medium, provided the original work is properly cited. 
연구가 많지 않다. 이에 본 연구에서는 국내 대학병원에 서 건강검진에 참여한 대상자들에서 당뇨병 가족력에 따 라 연령, $\mathrm{BMI}$ 에 따른 당뇨병의 관련성을 알아보고자 하 였다.

\section{재료 및 방법}

\section{연구 대상자}

한 대학병원 건강검진센터에서 검진을 받은 4,294명이 연구 대상자이었다(Cho et al., 2016; Sull et al., 2020). 이들에 대해서는 2004년부터 2013년 사이에 한국인 암 예방연구 사업(KCPS) 연구를 위하여 DNA 샘플이 얻어졌다(Jee et al., 2018). 이들 4,294명 중에서 1,810 명은 심혈관질환 환 자였다. 심혈관질환에 대한 정보는 국민건강보험공단 자 료 국제질병분류기호(10판)의 ICD 코드 I00-I99로 확인되 었다. 공복 시 혈당과 체질량지수의 결측값이 있는 대상 자는 분석에서 제외하였다. 따라서 최종 연구 대상자는 4,274 명이었다. 이들 중 1,790 명은 심혈관질환 환자였고, 2,484 명은 건강한 대상자였다. 여기서 건강한 대상자는 심혈관질환이 없는 사람으로 정의되었다. 1,790 명 심혈관 질환 환자 중 221 명이 당뇨병 환자였고, 203명이 당뇨병 가족력이 있었다. 2,484명 건강한 대상자 중 161 명이 당 뇨병 환자였고, 417 명이 당뇨병 가족력이 있었다. 전체 4,274 명 대상자 중에서 382 명이 당뇨병 환자였다. 또한 620 명이 당뇨병 가족력이 있었다. 본 연구는 을지대학교 $\operatorname{IRB}$ (연구윤리심의위원회)로부터 승인 받고 시행되었다 (EU20-02-01).

\section{조사내용}

체위자료는 검진조사자료 중에서 체중, 신장을 이용하 였다. 흡연상태는 '비흡연자', '과거 흡연자', '현재 흡연자' 로 나누었다. 통계분석에 이용된 변수로 체질량지수, 연 령 등을 분석하였다. 체질량지수는 체중 $(\mathrm{kg})$ 을 신장 $(\mathrm{m})$ 의 제곱으로 나누어 계산하였다. 공복 후 채취한 혈액으 로부터 공복 시 혈당, 지질 수치 등이 분석되었다. 분석 은 Hiitachi-7600 분석기(Hitachi, Ltd., Tokyo, Japan)를 이용 하였다. 상세한 표현형에 대한 기술은 이전 연구에서 기 술되었다(Cho et al., 2016; Jee et al., 2018).

\section{통계분석}

통계 프로그램은 SPSS version 25.0 (IBM Corp., Armonk, $\mathrm{NY}, \mathrm{USA}$ )를 이용하였고 $P$-value 0.05 미만을 통계적으로
유의한 것으로 정의하였고 양측 검정을 사용하였다. 분 석 결과는 주로 평균 \pm 표준편차로 기술되었다. 주요 통 계분석 방법은 다중 로지스틱 회귀분석을 이용하였다. 통 제된 혼란변수는 연령, 성별, 수축기혈압, $\mathrm{HDL}$ 콜레스테 롤, 체질량지수였다. 당뇨병에 대한 정의는 공복 시 혈당 이 $126 \mathrm{mg} / \mathrm{dL}$ 이상 또는 당뇨병 약물 복용력으로 정의되 었다. 그리고 전체 집단에서의 모든 연령의 기준은 중앙 값(median)인 52세로 정의하여 분석하였다. 또한 체질량 지수도 중앙값 24.33 으로 대상자를 나누어서 분석하였다.

\section{결 과}

본 연구 대상자의 평균 연령은 남성이 51.9세, 여성이 52.8 세이었다. 체질량지수는 남성의 평균이 24.8 , 여성이 23.5로 남성이 더 높았다. 공복 시 혈당의 경우도 남성이 $98.8 \mathrm{mg} / \mathrm{dL}$, 여성이 $93.1 \mathrm{mg} / \mathrm{dL}$ 로 남성이 더 높았다. 남성 대상자의 흡연률은 과거 흡연자는 $28.4 \%$, 현재 흡연자는 $26.9 \%$ 이었다. 또한 전체 대상자에서 당뇨병 유병 환자는 $8.9 \%$ 이었고, 당뇨병 가족력이 있는 대상자는 $14.5 \%$ 이었 다(Table 1).

당뇨병 가족력의 유무에 따른 당뇨병과의 로지스틱 회 귀분석은 연령, 성별, 수축기혈압, $\mathrm{HDL}$ 콜레스테롤, 체질 량지수 등을 통제하면서 이루어졌다(Table 2). 전체 대상자 에서 당뇨병 가족력이 있는 대상자가 당뇨병 가족력이 없는 대상자와 비교하여서 2.80 배 높은 당뇨병의 위험이 확인되었다(OR, 2.80; 95\% CI, 2.14 3.65). 또한, 남성 대상 자에서 당뇨병 가족력이 있는 대상자가 당뇨병 가족력이 없는 대상자와 비교하여서 2.76배 높은 당뇨병의 위험이 확인되었고(OR, 2.76; 95\% CI, 2.04 3.73), 여성 대상자에서 당뇨병 가족력이 있는 대상자가 당뇨병 가족력이 없는 대상자와 비교하여서 3.13배 높은 당뇨병의 위험이 확인 되었다(OR, 3.13; 95\% CI, 1.77 5.54). 즉, 남성과 여성에서 당뇨병 가족력과 당뇨병과의 관련성에서 큰 차이는 없었 다. 심혈관질환이 없는 건강한 대상자에서는 당뇨병 가족 력이 있는 대상자가 당뇨병 가족력이 없는 대상자와 비 교하여서 2.29배 높은 당뇨병의 위험이 확인되었다(OR, 2.29; 95\% CI, 1.57 3.35).

전체 대상자에 대해서 체질량지수와 연령의 중앙값을 기준으로 대상자를 나누어서 당뇨병 가족력의 유무에 따 른 당뇨병과의 관련성 분석이 연령, 성별, 수축기혈압, $\mathrm{HDL}$ 콜레스테롤, 체질량지수 등을 통제하면서 이루어졌 다(Table 3). 체질량지수가 중앙값 이하의 마른 대상자에서 
Table 1. General characteristics of the study population

\begin{tabular}{|c|c|c|c|c|}
\hline & & $\begin{array}{l}\text { All subjects } \\
(\mathrm{N}=4,274)\end{array}$ & $\begin{array}{l}\text { Subjects with CVD } \\
\qquad(\mathrm{N}=1,790)\end{array}$ & $\begin{array}{l}\text { Healthy subjects } \\
\qquad(\mathrm{N}=2,484)\end{array}$ \\
\hline & Mean \pm SD & Mean \pm SD & Mean \pm SD \\
\hline \multicolumn{2}{|l|}{ Age, year } & $52.2 \pm 10.2$ & $54.9 \pm 10.7$ & $50.2 \pm 9.4$ \\
\hline \multicolumn{2}{|l|}{ Weight, $\mathrm{kg}$} & $67.4 \pm 11.1$ & $68.4 \pm 10.7$ & $66.7 \pm 11.3$ \\
\hline \multicolumn{2}{|c|}{ Waist circumference, $\mathrm{cm}$} & $84.1 \pm 9.0$ & $86.0 \pm 8.6$ & $82.1 \pm 9.0$ \\
\hline \multicolumn{2}{|c|}{ Body mass index, $\mathrm{kg} / \mathrm{m}^{2}$} & $24.4 \pm 3.0$ & $24.9 \pm 2.9$ & $24.1 \pm 2.9$ \\
\hline \multicolumn{2}{|c|}{ Fasting blood sugar, mg/Dl } & $97.0 \pm 22.6$ & $100.4 \pm 25.6$ & $94.6 \pm 19.7$ \\
\hline \multicolumn{2}{|c|}{ Systolic blood pressure, $\mathrm{mmHg}$} & $121.9 \pm 14.5$ & $125.4 \pm 15.3$ & $119.4 \pm 13.3$ \\
\hline \multicolumn{2}{|c|}{ Diastolic blood pressure, $\mathrm{mmHg}$} & $78.2 \pm 10.8$ & $77.6 \pm 10.9$ & $78.7 \pm 10.7$ \\
\hline \multicolumn{2}{|l|}{ HDL-C, mg/dL } & $50.9 \pm 11.6$ & $49.5 \pm 10.4$ & $52.0 \pm 12.3$ \\
\hline \multicolumn{2}{|l|}{ LDL-C, mg/dL } & $116.8 \pm 31.8$ & $112.4 \pm 34.1$ & $119.2 \pm 30.1$ \\
\hline \multirow{2}{*}{\multicolumn{2}{|c|}{ Triglycerides, mg/dL }} & $143.7 \pm 96.7$ & $156.4 \pm 112.6$ & $134.8 \pm 82.5$ \\
\hline & & $\%$ & $\%$ & $\%$ \\
\hline \multirow{2}{*}{ Smoking status } & Ex & 28.4 & 33.3 & 25.2 \\
\hline & Current & 26.9 & 24.9 & 28.2 \\
\hline \multicolumn{2}{|c|}{ Cardiovascular disease } & 41.9 & 41.9 & 41.9 \\
\hline \multicolumn{2}{|l|}{ Diabetes $^{*}$} & 8.9 & 12.4 & 6.5 \\
\hline \multicolumn{2}{|c|}{ Family history of diabetes } & 14.5 & 11.3 & 16.8 \\
\hline
\end{tabular}

Abbreviations: SD, standard deviation; HDL-C, high-density lipoprotein cholesterol; LDL-C, low-density lipoprotein cholesterol; CVD, cardiovascular disease

*Diabetes was defined as fasting serum glucose $\geq 126 \mathrm{mg} / \mathrm{dL}$ or medication

Table 2. Odds ratios (OR) of the family history of diabetes for diabetes in the population $(n=4,274)$

\begin{tabular}{|c|c|c|c|c|c|c|c|}
\hline \multirow[b]{3}{*}{ Subjects } & \multirow[b]{3}{*}{ FHD } & \multirow{3}{*}{$\begin{array}{c}\text { Normal } \\
N(\%)\end{array}$} & \multicolumn{5}{|c|}{ Diabetes $^{*}$} \\
\hline & & & & \multicolumn{2}{|c|}{ Model 1} & \multicolumn{2}{|c|}{ Model 2} \\
\hline & & & $N(\%)$ & OR $(95 \%$ CI $)$ & $P$-value & OR $(95 \% \mathrm{CI})$ & $P$-value \\
\hline \multirow{2}{*}{$\begin{array}{l}\text { All } \\
(n=4,274)\end{array}$} & No & $3,367(86.5)$ & $287(75.1)$ & 1.00 (reference) & $<0.001$ & 1.00 (reference) & $<0.001$ \\
\hline & Yes & $525(13.5)$ & 95 (24.9) & $2.65(2.04 \sim 3.43)$ & & $2.80(2.14 \sim 3.65)$ & \\
\hline \multirow{2}{*}{ Men } & No & $2,273(87.1)$ & $222(75.0)$ & 1.00 (reference) & $<0.001$ & 1.00 (reference) & $<0.001$ \\
\hline & Yes & $336(12.9)$ & $74(25.0)$ & $2.67(1.98 \sim 3.59)$ & & $2.76(2.04 \sim 3.73)$ & \\
\hline \multirow{2}{*}{ Women } & No & $1,094(85.4)$ & $65(75.6)$ & 1.00 (reference) & $<0.001$ & 1.00 (reference) & $<0.001$ \\
\hline & Yes & $189(14.7)$ & $21(24.4)$ & $2.64(1.53 \sim 4.56)$ & & $3.13(1.77 \sim 5.54)$ & \\
\hline \multirow{2}{*}{$\begin{array}{l}\text { All Healthy } \\
(n=2,484)\end{array}$} & No & $1,949(83.9)$ & $118(73.3)$ & 1.00 (reference) & $<0.001$ & 1.00 (reference) & $<0.001$ \\
\hline & Yes & $374(16.1)$ & $43(26.7)$ & $2.29(1.57 \sim 3.34)$ & & $2.29(1.57 \sim 3.35)$ & \\
\hline
\end{tabular}

Model 1: Adjusted for age and sex, Model 2: Adjusted for age, sex, systolic blood pressure, HDL cholesterol, and body mass index

*Diabetes was defined as fasting serum glucose $\geq 126 \mathrm{mg} / \mathrm{dL}$ or medication

Abbreviations: OR, odds ratio; CI, confidence interval; FHD, family history of diabetes

당뇨병 가족력이 있는 대상자가 당뇨병 가족력이 없는 대상자와 비교하여서 2.98 배 높은 당뇨병의 위험이 확인 되었고(OR, 2.98; 95\% CI, 1.96 4.52), 체질량지수가 중앙값 이상인 대상자에서 당뇨병 가족력이 있는 대상자가 당뇨
병 가족력이 없는 대상자와 비교하여서 2.73배 높은 당뇨 병의 위험이 확인되었다(OR, 2.73; 95\% CI, 1.93 3.86). 즉, 체질량지수의 중앙값으로 대상자를 구분하여 분석하였을 때 당뇨병 가족력과 당뇨병과의 관련성에서 큰 차이는 없 
Table 3. Odds ratios (OR) of the family history of diabetes for diabetes in strata of median BMI and median age in Korean population $(n$ $=4,274)$

\begin{tabular}{|c|c|c|c|c|c|}
\hline \multirow[b]{2}{*}{ Subjects } & \multirow[b]{2}{*}{ FHD } & \multirow{2}{*}{$\begin{array}{c}\text { Normal } \\
N(\%)\end{array}$} & \multicolumn{3}{|c|}{ Diabetes $^{*}$} \\
\hline & & & $N(\%)$ & $\mathrm{OR}^{\mathrm{a}}(95 \% \mathrm{CI})$ & $P$-value \\
\hline \multirow[t]{2}{*}{$\mathrm{BMI}<24.33$} & No & $1,724(86.6)$ & $112(74.7)$ & 1.00 (reference) & \\
\hline & Yes & $267(13.4)$ & $38(25.3)$ & $2.98(1.96 \sim 4.52)$ & $<0.001$ \\
\hline \multirow[t]{2}{*}{$\mathrm{BMI}>=24.33$} & No & $1,643(86.4)$ & $175(75.4)$ & 1.00 (reference) & \\
\hline & Yes & $258(13.6)$ & 57 (24.6) & $2.73(1.93 \sim 3.86)$ & $<0.001$ \\
\hline \multirow[t]{2}{*}{ Age $<52$} & No & $1,652(83.7)$ & $70(63.6)$ & 1.00 (reference) & \\
\hline & Yes & $323(16.3)$ & $40(36.4)$ & $3.36(2.20 \sim 5.13)$ & $<0.001$ \\
\hline \multirow[t]{2}{*}{ Age $>=52$} & No & $1,715(89.5)$ & $217(79.8)$ & 1.00 (reference) & \\
\hline & Yes & $202(10.5)$ & $55(20.2)$ & $2.48(1.76 \sim 3.50)$ & $<0.001$ \\
\hline
\end{tabular}

${ }^{\text {a }}$ Adjusted for age, sex, systolic blood pressure, HDL cholesterol, and body mass index

*Diabetes was defined as fasting serum glucose $\geq 126 \mathrm{mg} / \mathrm{dL}$ or medication

$\mathrm{P}$ for interaction between obesity (BMI $>=24.33$ ) and $\mathrm{FHD}=0.7914, \mathrm{P}$ for interaction between older age (Age $>=52)$ and $\mathrm{FHD}=0.3712$

Abbreviations: OR, odds ratio; CI, confidence interval; FHD, family history of diabetes; BMI, body mass index

었다. 또한, 나이가 중앙값 이하의 젊은 대상자에서 당뇨 병 가족력이 있는 대상자가 당뇨병 가족력이 없는 대상 자와 비교하여서 3.36배 높은 당뇨병의 위험이 확인되었 고(OR, 3.36; 95\% CI, 2.20 5.13), 나이가 중앙값 이상인 대 상자에서 당뇨병 가족력이 있는 대상자가 당뇨병 가족력 이 없는 대상자와 비교하여서 2.48 배 높은 당뇨병의 위험 이 확인되었다(OR, $2.48 ; 95 \% \mathrm{CI}, 1.76$ 3.50). 즉, 나이의 중 앙값으로 대상자를 구분하여 분석하였을 때 당뇨병 가족 력과 당뇨병과의 관련성은 젊은 군에서 고령군보다 그 관련성이 약간 더 높았다.

\section{고 찰}

본 연구는 한 대학병원에서 건강검진을 받은 4,274 명의 한국인 남성, 여성을 대상으로 연령별, BMI 별로 당뇨병 가족력에 따른 당뇨병의 관련성을 분석한 결과이다. 기존 의 국내 선행 연구들에서도 당뇨병과 당뇨병 가족력의 관련성을 보고하였다. Kim et al. (2017)이 국민건강영양 조사 대상자들에 대하여 분석한 결과에서는 당뇨병 가 족력이 있는 대상자가 당뇨병 가족력이 없는 대상자와 비 교하여서 1.40 배 높은 당뇨병의 위험이 확인되었다(OR, 1.40; $95 \%$ CI, 1.13 1.73) (Kim et al., 2017). 최근의 다른 한 국인 대상자 연구에서는 당뇨병 가족력이 있는 대상자가 당뇨병 가족력이 없는 대상자와 비교하여서 1.57 배 높은 당뇨병의 위험이 확인되었다(OR, $1.58 ; 95 \% \mathrm{CI}, 1.37 \sim 1.82)$ (Ustulin et al., 2018). 본 연구에서는 당뇨병 가족력이 있
는 대상자가 당뇨병 가족력이 없는 대상자와 비교하여서 2.80 배 높은 당뇨병의 위험이 확인되었다. 즉, 이전 연구 보다 당뇨병 가족력의 더 높은 관련성을 확인하였다.

이전 한국인 대상 연구보다 당뇨병 가족력과 당뇨병과 의 더 높은 관련성을 보인 이유로는 이전 연구들이 대부 분 건강한 사람만을 대상으로 하였으나 본 연구 대상자 4,274 명 중에서 1,790 명은 심혈관질환 환자 $(41.9 \%)$ 인 것이 하나의 원인일 수 있겠다. 본 연구에서 심혈관질환이 없 는 건강한 대상자만을 분석했을 때 당뇨병 가족력이 있 는 대상자가 당뇨병 가족력이 없는 대상자와 비교하여서 2.29 배 높은 당뇨병의 위험을 확인하였다.

한편 최근 중국인과 일본인을 대상으로 한 연구에서 도 본 연구와 비슷하게 높은 관련성을 보고하였다. 최 근 중국인을 대상으로 한 연구에서는 당뇨병 가족력이 있는 대상자가 당뇨병 가족력이 없는 대상자와 비교하 여서 3.57배 높은 당뇨병의 위험이 확인되었다(OR, 3.57; $95 \%$ CI, 2.95 4.33) (Ye et al., 2021). 그리고 2013년의 일본 인 대상 연구에서는 당뇨병 가족력이 있는 대상자가 당 뇨병 가족력이 없는 대상자와 비교하여서 1.84 배 높은 당 뇨병의 위험을 보고하였고, 특히 어머니가 환자인 대상자 에서는 2.56 배의 관련성을 보고하였다(OR, $2.56 ; 95 \% \mathrm{CI}$, 1.67 3.92) (Sakurai et al., 2013).

최근 일본인을 대상으로 한 대규모 코호트 연구에서는 체질량지수의 변화가 제 2 형 당뇨병 발생과 높은 관련이 있음을 보고했다(Okada et al., 2021). 중년의 스웨덴 남성, 여성을 대상으로 한 연구에서는 체질량지수가 30 이하의 
마른 대상자에서 당뇨병 가족력이 있는 대상자가 당뇨병 가족력이 없는 대상자와 비교하여서 3.9배 높은 당뇨병 의 위험이 확인되었고, 체질량지수가 30 이상인 비만한 대상자에서 당뇨병 가족력이 있는 대상자가 당뇨병 가족 력이 없는 대상자와 비교하여서 11.1배 높은 당뇨병의 위 험이 확인되었다(OR, $11.1 ; 95 \% \mathrm{CI}, 4.8$ 25.7). 즉, 체질량 지수 30 을 기준으로 대상자를 구분하여 분석하였을 때 당뇨병 가족력과 당뇨병과의 관련성에서 큰 차이가 있었 다(Hilding et al., 2006). 그리고 2013년의 중국인과 핀란드 인들을 대상으로 한 연구에서도 체질량지수 30 이상인 비만한 군에서 당뇨병 가족력과 당뇨병과의 관련성이 더 큰 것을 확인하였다(Ning et al., 2013). 그러나 2013년의 일 본인 대상 연구에서는 본 연구 결과와 비슷하게 체질량 지수 25 를 기준으로 대상자를 구분하여서 당뇨병 가족력 과 당뇨과의 관련성을 보았을 때 큰 차이가 없다고 보고 하였다(Sakurai et al., 2013). 본 연구에서는 체질량지수의 중앙값으로 대상자를 구분하여 분석하였을 때 당뇨병 가 족력과 당뇨병과의 관련성에서 큰 차이는 없었다.

본 연구에서는 당뇨병 가족력과 당뇨병과의 높은 관련 성을 확인하였다. 또한 연령에 따라서 대상자를 구분하여 분석하였을 때 연령의 중앙값인 52세 미만의 젊은 대상 자에서 그 관련성이 더 높았다. 최근에 45세 이상의 호주 인들을 대상으로 한 코호트 연구에서도 당뇨병 가족력이 있으면 당뇨병 발생 위험이 1.65배 높음을 보고했다(Zhang et al., 2020). 최근 20 44세의 젊은 성인을 대상으로 한 다 른 연구에서는 피마 인디언(Pima Indians)보다 남아시아 인(South Asians)들에서 당뇨병 가족력과 당뇨병 발생 위 험의 관련성이 높음을 보고했다(Narayan et al., 2021). 호 주 청소년들을 대상으로 한 최근 연구에서는 당뇨병 가 족력이 있는 청소년들이 비만, 수면 습관 등에서 가족력 이 없는 청소년보다 나쁜 습관을 가지고 있음을 보고했 다(Downing et al., 2020). 한편 최근 우리나라 성인을 대 상으로 한 연구에서는 당뇨병 가족력이 있는 사람에서 상대적으로 높은 경동맥 내막 두께를 보고했다(Shim et al., 2021).

당뇨병 가족력과 당뇨병과의 관련성을 본 연구서 분석 했을 때 남성보다 여성에서 조금 더 높은 관련성을 확인 했다. 연구 대상자의 평균 연령은 남성이 51.9세, 여성이 52.8 세로 여성이 높았다. 또한 체질량지수, 공복 시 혈당, 혈압도 남성이 여성보다 높았다. 특히 남성 대상자의 현 재 흡연률은 $37.3 \%$, 여성의 현재 흡연률은 $3.9 \%$ 로 차이 가 컸다.
본 연구는 단면 연구의 한계점을 가지고 있다. 또한 당 뇨병을 공복 시 혈당과 당뇨병 약물 복용력으로 정의했 고, $\mathrm{HbAlC}$ 수치는 당뇨병 정의에 포함하지 못하였다. 본 연구의 결과는 고령자보다는 52 세 미만의 젊은 군에서 당뇨병 가족력이 당뇨병 발생 위험과 관련성이 높음을 보고한 것에 의의가 있다. 이는 젊은 군을 대상으로 연구 한 외국의 결과들과 일치한다(Zhang et al., 2020; Narayan et al., 2021). 이에 대하여는 추후 장기적인 전향적인 코호 트 연구가 필요하겠다.

\section{ACKNOWLEDGEMENT}

This paper was funded by the Basic Science Research Program of the National Research Foundation of Korea through the Ministry of Education, Science, and Technology (2018R1D1A1B07050834) and funded by the Korea medical institute (KMI) in 2021.

\section{CONFLICT OF INTEREST}

The authors declare that they have no conflict of interest.

\section{REFERENCES}

Cho ER, Jee YH, Kim SW, Sull JW. Effect of obesity on the association between MYL2 (rs3782889) and high-density lipoprotein cholesterol among Korean men. J Hum Genet. 2016. 61: 405-409.

Downing KL, Hesketh KD, Timperio A, Salmon J, Moss K, Mishra G. Family history of non-communicable diseases and associations with weight and movement behaviours in Australian school-aged children: a prospective study. BMJ Open. 2020. 10: e038789.

Hilding A, Eriksson AK, Agardh EE, et al. The impact of family history of diabetes and lifestyle factors on abnormal glucose regulation in middle-aged Swedish men and women. Diabetologia. 2006. 49: 2589-2598.

Jee SH, Sull JW, Park J, et al. Body-mass index and mortality in Korean men and women. N Engl J Med. 2006. 355: 779-787.

Jee YH, Emberson J, Jung KJ, et al. Cohort Profile: The Korean Cancer Prevention Study-II (KCPS-II) Biobank. Int J Epidemiol. 2018. 47: 385-386f.

Kaprio J, Tuomilehto J, Koskenvuo M, et al. Concordance for type 1 (insulin-dependent) and type 2 (non-insulindependent) diabetes mellitus in a population-based cohort of twins in 
Finland. Diabetologia. 1992. 35: 1060-1067.

Kim EH, Bae SG, Kim KY, Na YJ. Impaired Fasting Glucose Rate by Diabetes Family History. J Health Info Stat. 2017. 42: 63-69.

Korean Diabetes Association, Korea Centers for Disease Control and Prevention (KCDC). Diabetes fact sheet in Korea 2012. Available at www.diabetes.or.kr/temp/DiabetesFact\%20sheet 2012_en.pdf [Accessed on 2 January 2017].

Narayan KMV, Kondal D, Kobes S, et al. Incidence of diabetes in South Asian young adults compared to Pima Indians. BMJ Open Diabetes Res Care. 2021. 9: e001988.

Ning F, Pang Z, Laatikainen T, et al. Joint effect of family history of diabetes with obesity on prevalence of type 2 diabetes mellitus among Chinese and Finnish men and women. Can J Diabetes. 2013. 37: 65-71.

Ogata E, Asahi K, Yamaguchi S, et al. Low fasting plasma glucose level as a predictor of new-onset diabetes mellitus on a large cohort from a Japanese general population. Sci Rep. 2018. 8: 13927.

Okada H, Hamaguchi M, Habu M, et al. Association between variability in body mass index and development of type 2 diabetes: Panasonic cohort study. BMJ Open Diabetes Res Care. 2021. 9: e002123.

Park HS, Jeong JG, Yu JH. The relationship between factors of metal-bolic syndrome in Korean adult males and the parents' family history of diabetes. J Korea Inst Electron Commun Sci. 2013. 8: 779-784.

Sakurai M, Nakamura K, Miura K, et al. Family history of diabetes, lifestyle factors, and the 7-year incident risk of type 2 diabetes mellitus in middle-aged Japanese men and women. J Diabetes Investig. 2013. 4: 261-268.

Shaw JT, Purdie DM, Neil HA, Levy JC, Turner RC. The relative risks of hyperglycaemia, obesity and dyslipidaemia in the relatives of patients with Type II diabetes mellitus. Diabetologia. 1999. 42: 24-27.
Shim SY, Lee GB, Shim JS, Jung SJ, Kim HC. Association between a family history of diabetes and carotid artery atherosclerosis in Korean adults. Epidemiol Health. 2021. 43: e2021049.

Song MG, Koh YH, Kim JB, Lee DA, Noh BR, Kim HJ. Association between Family History of Diabetes Mellitus and Health Behaviors among Korean Adults. Korean J Fam Pract. 2017. 7: 411-417.

Sull JW, Kim G, Jee SH. Association of MC4R (rs17782313) with diabetes and cardiovascular disease in Korean men and women. BMC Med Genet. 2020. 21: 160.

Unwin N, Whiting D, Guariguata L, Ghyoot G, Gan D. IDF diabetes atlas. Brussels, Belgium: International Diabetes Federation. 2011. p. 11-74.

Ustulin M, Rhee SY, Chon S, et al. Importance of family history of diabetes in computing a diabetes risk score in Korean prediabetic population. Sci Rep. 2018. 8: 15958.

Weijnen CF, Rich SS, Meigs JB, Krolewski AS, Warram JH. Risk of diabetes in siblings of index cases with Type 2 diabetes: implications for genetic studies. Diabet Med. 2002. 19: 41-50.

Ye C, Niu J, Zhao Z, et al. Genetic susceptibility, family history of diabetes and healthy lifestyle factors in relation to diabetes: A gene-environment interaction analysis in Chinese adults. J Diabetes Investig. 2021. 12: 2089-2098.

Zhang H, Rogers K, Sukkar L, et al. Prevalence, incidence and risk factors of diabetes in Australian adults aged $\geq 45$ years: A cohort study using linked routinely-collected data. J Clin Transl Endocrinol. 2020. 22: 100240.

https://oi.org/10.15616/BSL.2021.27.4.317

Cite this article as: Ko E, Sull JW. The Relationship between Family History of Diabetes and Diabetes by BMI and Age in Korean Men and Women. Biomedical Science Letters. 2021. 27: 317-322. 